\title{
Effect of Hirulog-Like Peptide on Balloon Catheter Injury-Induced Neointimal Formation in Femoral Arteries of Minipigs and Relationship with Inflammatory Mediators
}

\author{
Xiao-Feng Tang ${ }^{a, c}$ Jian-Jun Liu ${ }^{a, c}$ Yong-Jie Wu ${ }^{a, c}$ Ke-Ming Chen ${ }^{b}$ Yong Jin ${ }^{b}$ \\ Ping-Jin Gao ${ }^{\text {a, c }}$ Ding-Liang Zhu ${ }^{\text {a, c }}$ Garry X. Shen ${ }^{d}$ \\ aShanghai Key Laboratory of Vascular Biology, ${ }^{\mathrm{b}}$ Department of Radiology, and ${ }^{\mathrm{c}}$ Ruijin Hospital, Shanghai Institute \\ of Hypertension, Shanghai Jiaotong University School of Medicine, Shanghai, China; ${ }^{d}$ Departments of Internal \\ Medicine and Physiology, University of Manitoba, Winnipeg, Man., Canada
}

\section{Key Words}

Hirulog-like peptide $\cdot$ Balloon catheter injury $\cdot$ Neointimal

formation $\cdot$ Coagulation

\begin{abstract}
Vascular intervention-induced neointimal formation is a major drawback for managing atherosclerotic cardiovascular diseases using invasive vascular procedures. Our previous studies demonstrated that hirulog-like peptide (HLP) reduced balloon catheter dilation-induced neointimal formation or restenosis in carotid arteries of rats or atherosclerotic rabbits with less interruption in coagulation or bleeding than heparin or hirulog-1. The present study examined the effect of HLP on balloon catheter injury-induced neointimal formation in femoral arteries of minipigs. Intravenous infusion of HLP $(1.6 \mathrm{mg} / \mathrm{kg} / \mathrm{h}$ for $4 \mathrm{~h}$ started $0.5 \mathrm{~h}$ before the intervention) or unfractured heparin (50 U/kg/h for $4 \mathrm{~h}$ ) significantly reduced neointimal formation in femoral arteries 4 weeks after intervention compared with the vehicle. Heparin, but not HLP, significantly prolonged activated partial thromboplastin time. HLP or heparin significantly reduced vascular intervention-induced increases in C-reactive protein, $\mathrm{P}$-selectin and interleukin- 6 in serum. HLP, but not hep-
\end{abstract}

arin, normalized vascular injury-induced increase in P-selectin in platelets. The results of the present study suggest that HLP is an effective agent for preventing balloon catheter injury-induced neointimal formation in femoral arteries of minipigs. The beneficial effects of HLP on vascular injury-induced neointimal formation may partially result from its inhibition on inflammatory mediators.

Copyright $\odot 2009$ S. Karger AG, Basel

\section{Introduction}

Angioplasty or stents have been widely applied in patients with clinical and angiographical coronary stenosis to enlarge the vascular lumen and increase blood supply to the heart. Vascular intervention-induced neointimal formation is a major concern for the treatment of atherosclerotic cardiovascular diseases $[1,2]$. Even with stateto-art technology, $10-15 \%$ of receivers of percutaneous coronary intervention with drug-eluting stents require additional revascularization [3]. An effective and safe approach for the prevention of vascular injury-induced neointimal formation is highly demanded. The underlying mechanism for intravascular injury-induced neointi-

\section{KARGER}

Fax +41613061234 E-Mail karger@karger.ch www.karger.com
(C) 2009 S. Karger AG, Basel

$1018-1172 / 10 / 0473-0262 \$ 26.00 / 0$

Accessible online at:

www.karger.com/jvr
Dr. Garry X. Shen

Diabetes Research Group, University of Manitoba

835-715 McDermot Ave

Winnipeg, MB R3E 3P4 (Canada)

Tel. +1 204789 3816, Fax +1 204789 3987, E-Mail gshen@ms.umanitoba.ca 
mal formation remains unclear. Angioplasty impairs endothelial integrity. Extracellular matrix in the vascular wall, which is normally protected by endothelium, may interact with blood components and stimulate the formation of thrombin during an acute phase after vascular intervention [4]. Intravascular thrombosis often occurs shortly after the intervention. Thrombin is a serine protease generated through the activation of the coagulation cascade. It plays a critical role in a number of biological processes potentially relevant to neointimal formation, such as coagulation, fibrinolysis, cell proliferation, inflammation and wound healing [5]. Previous studies indicated that thrombin-specific inhibitors, hirudin or bivalirudin (hirulog-1), reduced vascular injury-induced neointimal formation or restenosis in small animal models [6-8]. Results of large clinical trials failed to find longterm benefits of hirudin or hirulog-1 in patients receiving vascular interventions, which was partially due to increased hematologic complications $[9,10]$. Our group designed a new thrombin inhibitor peptide, hirulog-like peptide (HLP). Intravenous infusion of HLP prevented neointimal formation or restenosis in rats or atherosclerotic rabbits. The sequence of $\mathrm{HLP}_{20-31}$ is adopted from hirulog-1 $1_{9-20}$, which aims at the amino binding site of thrombin. The amino terminal of HLP contains a sequence homology to a distal portion of the extracellular domain of thrombin receptor. Therefore, HLP provides dual inhibition of the binding of thrombin to thrombin receptor, which potentially provides more efficient inhibition of thrombin receptor-dependent cellular activities in comparison with hirulog-1 or nonspecific thrombin inhibitor, such as heparin [11]. The effects of HLP on prolongation of coagulation or bleeding time were significantly attenuated in rats or rabbits compared with bivalirudin or unfractured heparin $[11,12]$. Miniature swine or minipig is an ideal model for examining the efficacy of drugs against vascular injury-induced neointimal formation for potential clinical application. The effect of HLP on vascular injury-induced neointimal formation in large animals has not been documented.

Our previous studies demonstrated that HLP infusion reduced the abundance of platelet-derived growth factor, transforming growth factor- $\beta$ and tissue factor in the arterial wall of rats or rabbits $[11,12]$. Inflammation plays a critical role in the development of vascular restenosis. Previous studies demonstrated that the levels of several inflammatory markers, including C-reactive protein (CRP), P-selectin and interleukin-6 (IL-6), were elevated after angioplasty $[13,14]$. The effect of HLP on inflammatory mediators has not been described.
The present study examined the effect of HLP on balloon catheter dilation-induced neointimal formation in minipigs. The impact of HLP on CRP, P-selectin and IL6 in minipigs was investigated.

\section{Methods}

\section{Animals}

Guizhou minipigs (males, 10-15 kg, $\mathrm{n}=15$ ) were obtained from Jiaotong University Agriculture College and housed in the Department of Animals for Scientific Research, Jiaotong University, in separate pens under regular daylight at $18-25^{\circ} \mathrm{C}$. They were fed 200-250 g of commercial plan porcine fodder (Purina Farun Chow containing $21 \%$ of protein, $69 \%$ of carbohydrate and $10 \%$ of fat) twice a day and allowed free access to tap water. Animals were randomized to 3 pharmacological treatment groups (saline, HLP and heparin group, $\mathrm{n}=5$ /group). The protocol of animal usage was conformed to the Guides for the Care and Usage of Laboratory Animals published by the National Institutes of Health (publication No. 85-23, revised 1996).

\section{Vascular Injury}

Minipigs were sedated with an intramuscular injection of ketamine (15 mg/kg body weight). Anesthesia was maintained with repeated dosages of intravenous pentobarbital $(25 \mathrm{mg} / \mathrm{kg})$ with a 30 -min interval. Respiratory secretion was inhibited by intravascular injection of atropine $(0.05 \mathrm{mg} / \mathrm{kg})$. Animals were intubated using endotracheal tubes after the start of anesthesia. Right common carotid arteries and the internal jugular vein were surgically exposed. A 20 -gauge venous cannula was placed in the right internal jugular veins as a port of blood sample. A 6-french introducer sheath (Terumo, Somerset, N.J., USA) was inserted into the right carotid artery. A balloon dilation catheter was inserted into the right carotid artery through the sheath and was advanced under fluoroscopic guidance to both right and left common femoral arteries over a 0.018-inch guidewire (Cordis, Miami, Fla., USA). Five inflations were performed at $10 \mathrm{~atm}$ for $1 \mathrm{~min} / \mathrm{each}$ with a 60 -second interval in each femoral artery. The dilation ratio between the balloon and artery was 1.2:1 using the artery segment as a reference. Angiograms of common femoral arteries were obtained before and after angioplasty to confirm the dilation of the vascular lumen.

\section{Pharmacological Treatment}

HLP (FPESKATNATLDPRPGGGGNGDFEEIPEEYLQ) was designed as previously described [11]. The peptide was purified using high-performance liquid chromatography and freshly dissolved in saline. Heparin was obtained from Gibco BRL (Burlington, Ont., Canada). Intravenous infusions of HLP $(1.6 \mathrm{mg} / \mathrm{kg} / \mathrm{h})$, heparin $(50 \mathrm{U} / \mathrm{kg} / \mathrm{h})$ or vehicle control ( $0.9 \%$ saline) were administered via ear vein using a peristaltic pump at a speed of 12.5 $\mathrm{ml} / \mathrm{h}$. The regimen of HLP administration was optimized in our previous studies in rat model [11]. The dosage of heparin was described in a previous study in large animals [15]. The infusions were started $0.5 \mathrm{~h}$ before angioplasty and maintained for $4 \mathrm{~h}$. 


\section{Histological Analysis}

Four weeks after vascular injury and treatment, animals received euthanasia with sodium pentobarbital $(60 \mathrm{mg} / \mathrm{kg})$. Results from our pilot experiments indicated that neointimal formation in femoral arteries reached their maximal extent 4 weeks after balloon catheter injury in minipigs. The abdominal aorta and inferior vena cava were surgically exposed and ligated. The vascular system was flushed via the aortic cannula with $150 \mathrm{ml}$ of normal saline $\left(37^{\circ} \mathrm{C}\right)$ and 1 liter of $4 \%$ phosphate-buffered $(0.1 \mathrm{M}, \mathrm{pH} 7.4)$ formaldehyde $\left(37^{\circ} \mathrm{C}\right)$ at a pressure of $120 \mathrm{~mm} \mathrm{Hg}$. Segments of injured femoral arteries were excised. Arterial fragments were dehydrated in increasing concentrations of ethanol and xylene and embedded in paraffin. Vascular fragments in paraffin blocks were cut into 5 - $\mu \mathrm{m}$ sections and mounted on glass slides. The slides were subject to Weigert's elastin stain. Histological analysis was conducted using the Nikon Microprojection System and the Qwin image analysis system (Leica, Bannockburn, Ill., USA) by observers without knowledge in animal treatment or grouping. The neointimal area was defined as area between the lumen surface and the internal elastic lamina. Media represented the area between the internal and external elastic lamina. The neointima/ media ratio was defined as the ratio between the neointimal area and media. The residual lumen was the area of the vascular lumen after vascular injury. Stenosis was presented in percentages of neointimal area/(residual lumen + neointimal area).

\section{Coagulation and Platelet Aggregation}

Blood samples were drawn from internal jugular veins into tubes containing $38 \mathrm{~g} / \mathrm{l}$ sodium citrate solution $(9: 1, \mathrm{v} / \mathrm{v})$ at baseline, immediately after balloon angioplasty and after pharmacological infusion. Activated partial thromboplastin time (aPTT), prothrombin time $(\mathrm{PT})$ and fibrinogen $(\mathrm{Fg})$ were measured using the ACL 3000-Plus system (Beckman, Miami, Fla., USA). Plateletrich plasma was isolated through centrifugation at $200 \mathrm{~g}$ for 15 min at $22^{\circ} \mathrm{C}$. ADP-induced platelet aggregation in platelet-rich plasma was performed with a 4-channel aggregometer (Chronolog, Havertown, Pa., USA) within 2 h after blood collection. Each sample of platelet-rich plasma was counted for platelets and was standardized to 300,000 platelets $/ \mathrm{mm}^{3}$ by adjusting the volume using autologous platelet-poor plasma. ADP at $10 \mu \mathrm{M}$ was used in platelet aggregation analysis.

\section{Measurement of Inflammatory Markers in Serum}

High-sensitivity CRP (hsCRP) and P-selectin in serum were measured using enzyme-linked immunosorbent assay (ELISA) kits (Uscnlife, Wuhan, China), according to the manufacturer's instruction. The sensitivity of hsCRP was $0.03 \mu \mathrm{g} / \mathrm{ml}$, and the sensitivity of P-selectin was $0.15 \mathrm{ng} / \mathrm{ml}$. Serum concentrations of IL- 6 were determined using IL-6 ELISA kits (R\&D, Minneapolis, Minn., USA) with a low detection limitation of $10 \mathrm{pg} / \mathrm{ml}$.

\section{Platelet P-Selectin}

Blood was collected from the internal jugular vein cannula directly into polypropylene tubes containing $0.4 \mathrm{ml}$ of acid citratedextrose solution ( $\mathrm{pH}$ 6.5, 1:9, v/v) before, $2 \mathrm{~h}$ and 4 weeks after vascular intervention. Total platelet counts were obtained using a Coulter counter. Platelets were isolated from blood through centrifugation at $200 \mathrm{~g}$ at room temperature for $15 \mathrm{~min}$ to obtain platelet-rich plasma. Platelets in platelet-rich plasma were pelleted using centrifugation at $1,500 \mathrm{~g}$ for $10 \mathrm{~min}$ at room temperature. Platelets were then washed 3 times using a buffer ( $\mathrm{pH}$ 6.5) containing 185.7 mM sodium citrate, $14 \mathrm{~mm}$ citric acid, $209.8 \mathrm{~mm}$ dextrose, $9.9 \mathrm{mM}$ $\mathrm{KCl}$ and $0.3 \%$ bovine serum albumin. Washed platelets were pelleted and then resuspended in a buffer containing $1 \%$ sodium dodecyl sulfate, $1 \mathrm{~mm}$ sodium vanadate and $10 \mathrm{~mm}$ Tris ( $\mathrm{pH}$ 7.4). The frozen platelet preparation was thawed and passed through a 26 gauge needle, then sonicated for $6 \mathrm{~min}$. The platelet lysate was centrifuged at $12,000 \mathrm{~g}$ for $5 \mathrm{~min}$ at $4^{\circ} \mathrm{C}$ to remove insoluble particles. Total protein concentrations in the supernatant were determined using BCA-200 protein assay reagents (Thermo Pierce, Waltham, Mass., USA). Abundance of P-selectin in the platelet lysate was assessed using Western blotting. Platelet lysate proteins were analyzed on $8 \%$ sodium dodecyl sulfate-polyacrylamide gel electrophoresis. Proteins were transferred onto polyvinylidene difluoride membranes using Trans-Blot SD semi-dry transfer cell (Bio-Rad, Hercules, Calif., USA). P-selectin on the membrane was detected using goat anti-human P-selectin antibody (1:1,000 dilution), antigoat IgG-horseradish peroxidase conjugates antibody $(1: 2,000)$ and the Opti-4CN substrate kit (Bio-Rad). The intensities of the protein bands on the membrane were analyzed using Qwin automated digitizing system and normalized with the abundance of $\beta$-actin in the corresponding platelet lysate.

\section{Statistics}

A one-way ANOVA test was performed for comparisons of variables among multiple groups. The level of significance was defined as $\mathrm{p}<0.05$.

\section{Results}

\section{Effect of HLP Treatment on Balloon Catheter}

Dilation-Induced Neointimal Formation

Balloon catheter dilation induced evident neointimal formation in femoral arteries of minipigs and reduced the vascular lumen 4 weeks after vascular injury in control animals receiving saline alone (fig. 1a). Neointimal formation was characterized by increases in the neointimal area, neointima/media ratio and stenosis (fig. 2). In minipigs treated with $50 \mathrm{U} / \mathrm{kg} / \mathrm{h}$ of unfractured heparin or 1.6 $\mathrm{mg} / \mathrm{kg} / \mathrm{h}$ of HLP for $4 \mathrm{~h}$ initiated $0.5 \mathrm{~h}$ before balloon catheter injury, significantly reduced neointimal formation in the femoral arteries was detected compared with vehicle controls ( $\mathrm{p}<0.05$ or $\mathrm{p}<0.01, \mathrm{n}=5$ /group; fig. 1 , 2). No significant difference in the neointima/media ratio or stenosis was detected in femoral arteries from animals treated with heparin or HLP.

\section{Influence of HLP on Coagulation and Platelet Aggregation}

Coagulation and platelet aggregation were evaluated by measuring PT, aPTT, Fg and ADP-induced platelet aggregation before, 2 and $4 \mathrm{~h}$ after the pharmacological infusions. Heparin treatment elongated aPTT in minipigs 


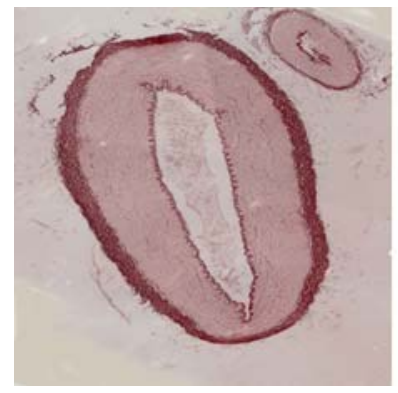

a

Saline

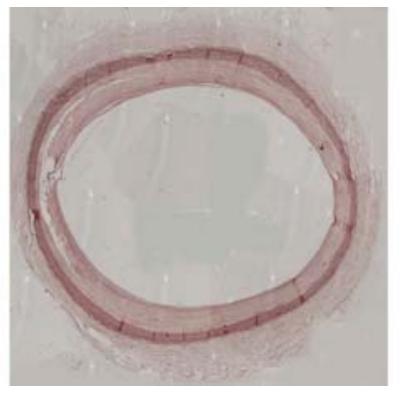

HLP

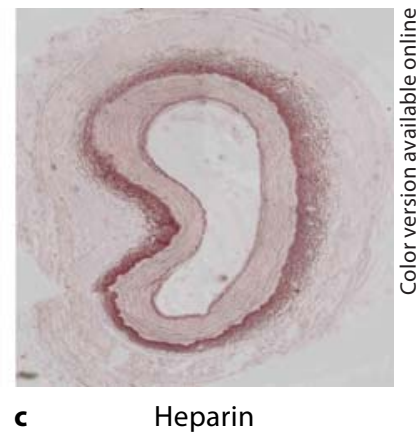

Heparin
Fig. 1. Effect of HLP on balloon catheter injury-induced neointimal formation in minipig femoral arteries. Femoral arteries of minipigs were injured by balloon catheter. Animals received intravenous infusion with one of the following agents: $0.9 \%$ saline (a), $1.6 \mathrm{mg} / \mathrm{kg} / \mathrm{h}$ of HLP (b), or $50 \mathrm{U} / \mathrm{kg} / \mathrm{h}$ of heparin (c). Infusions via the ear vein were started $0.5 \mathrm{~h}$ before the intervention and lasted for $4 \mathrm{~h}$. Four weeks after the intervention, femoral arteries were surgically isolated. Cross-sections of injured arterial fragments on slides were stained with Weigert's method. Images were captured under light microscopy. $\times 5$.

Table 1. Effects of HLP and heparin on PT, aPTT, Fg and platelet aggregation in minipigs

\begin{tabular}{llllll}
\hline Time & Treatment & PT, & aPTT, & Fg, mg/ml & PA, \% \\
\hline $0 \mathrm{~h}$ & saline & $10.78 \pm 0.98$ & $24.19 \pm 9.78$ & $572 \pm 103$ & $69.60 \pm 18.56$ \\
& heparin & $11.94 \pm 0.94$ & $26.41 \pm 5.27$ & $654 \pm 156$ & $82.60 \pm 28.27$ \\
\multirow{3}{*}{$2 \mathrm{~h}$} & HLP & $12.01 \pm 1.20$ & $22.27 \pm 7.01$ & $527 \pm 172$ & $64.60 \pm 12.14$ \\
& saline & $13.11 \pm 1.81$ & $56.17 \pm 12.90$ & $590 \pm 102$ & $84.00 \pm 21.79$ \\
& heparin & $14.05 \pm 2.77$ & $77.98 \pm 14.43^{\mathrm{a}}$ & $646 \pm 179$ & $98.20 \pm 12.32$ \\
$4 \mathrm{~h}$ & HLP & $13.48 \pm 2.22$ & $35.83 \pm 11.81^{\mathrm{a}, \mathrm{b}}$ & $522 \pm 162$ & $83.20 \pm 18.75$ \\
& saline & $11.28 \pm 1.13$ & $26.15 \pm 13.20$ & $535 \pm 130$ & $88.80 \pm 17.08$ \\
& heparin & $13.44 \pm 3.28$ & $76.83 \pm 27.08^{\mathrm{a}}$ & $639 \pm 164$ & $87.20 \pm 20.61$ \\
& HLP & $12.90 \pm 2.27$ & $30.02 \pm 10.89^{\mathrm{b}}$ & $499 \pm 170$ & $83.20 \pm 16.15$ \\
\hline
\end{tabular}

Values are expressed as the mean $\pm \mathrm{SD}$ ( $\mathrm{n}=5$ animals/group). PA $=$ Platelet aggregation. Minipigs with balloon catheter injury were intravenously infused with saline as control, $50 \mathrm{U} / \mathrm{kg} / \mathrm{h}$ of heparin or $1.6 \mathrm{mg} / \mathrm{kg} / \mathrm{h}$ of HLP for $4 \mathrm{~h}$ starting $0.5 \mathrm{~h}$ before the injury. PT, aPTT, Fg and platelet aggregation were determined before, 2 or $4 \mathrm{~h}$ after the start and $15 \mathrm{~min}$ after the end of the infusion.

${ }^{\mathrm{a}} \mathrm{p}<0.05$, versus controls; ${ }^{\mathrm{b}} \mathrm{p}<0.05$, versus heparin.

close to 3 times compared with vehicle controls $(\mathrm{p}<0.05)$. HLP did not significantly prolong aPTT compared with controls. The length of aPTT in the HLP group was significantly shorter than that in heparin-treated animals $(\mathrm{p}<0.05)$. No significant change was detected in PT, Fg or platelet aggregation before and after pharmacological interventions among animals with various treatments (table 1).

\section{Impact of HLP on Serum hsCRP, P-Selectin and IL-6}

Balloon catheter injury significantly increased the levels of hsCRP $4 \mathrm{~h}$ after the intervention in minipigs receiving saline only $(\mathrm{p}<0.05)$. The levels of $\mathrm{P}$-selectin were increased 2 or $4 \mathrm{~h}$ after vascular injury in similar extents $(\mathrm{p}<0.05$ or $\mathrm{p}<0.01)$. The levels of IL- 6 at $2 \mathrm{~h}$, but not at $4 \mathrm{~h}$, after injury were significantly increased in minipigs receiving the vehicle $(\mathrm{p}<0.05)$. Treatment with HLP or heparin normalized the levels of hsCRP and P-selectin induced by vascular injury. HLP, but not heparin, significantly reduced the level of IL- 6 in the blood circulation of minipigs ( $\mathrm{p}<0.05$; fig. 3 ).

\section{Effect of HLP Treatment on Abundance of P-Selectin in Platelets}

The effect of HLP on platelet P-selectin was examined in minipigs $2 \mathrm{~h}$ or 4 weeks after vascular injury. The mo- 

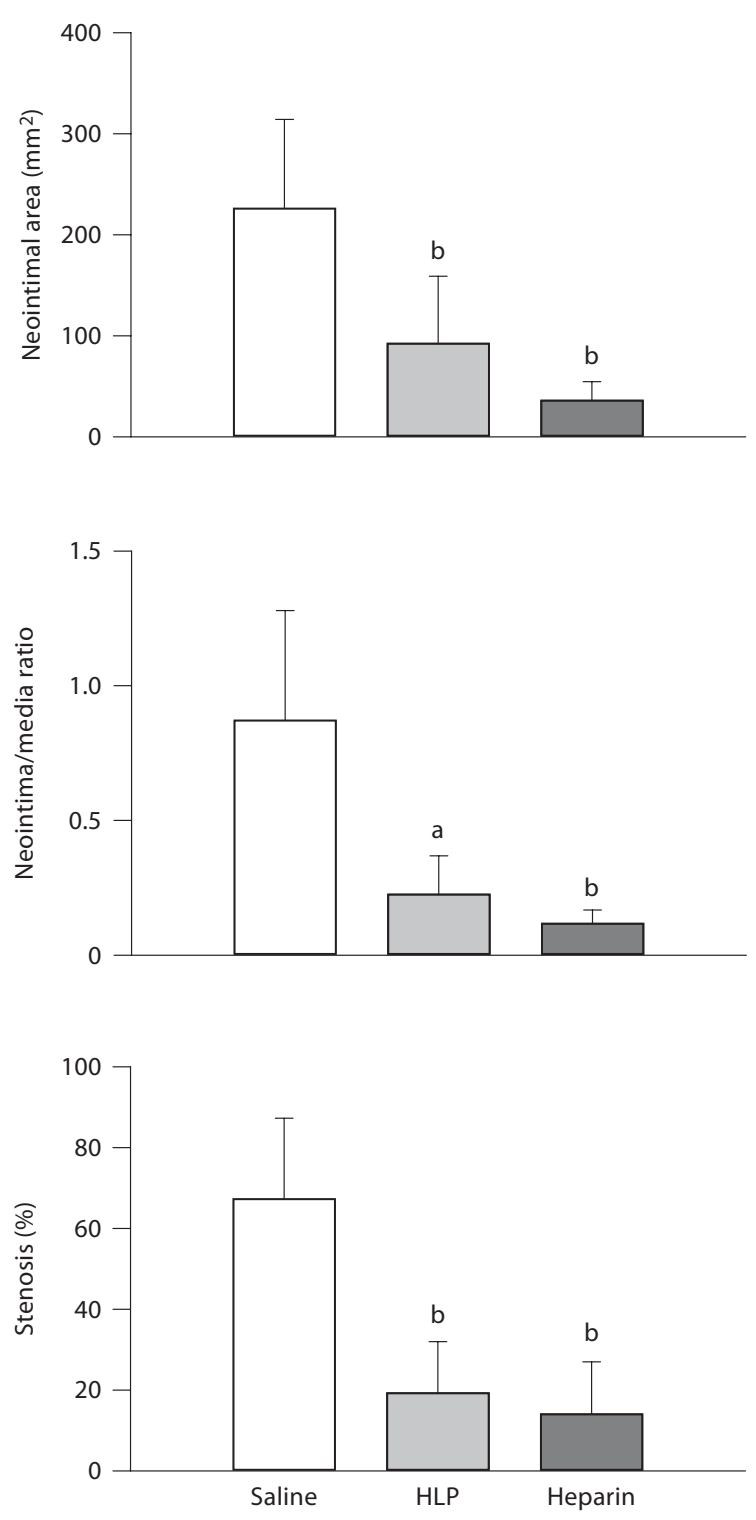

Fig. 2. Comparison of the effects of HLP and heparin on neointimal formation and vascular stenosis in the minipig femoral artery induced by balloon catheter injury. Femoral arteries of minipigs ( $\mathrm{n}=5$ animals/group) were injured by balloon catheter. Intravenous infusions of saline, HLP $(1.6 \mathrm{mg} / \mathrm{kg} / \mathrm{h})$ or heparin $(50$ $\mathrm{U} / \mathrm{kg} / \mathrm{h}$ ) via ear vein were started $0.5 \mathrm{~h}$ prior to the intervention and lasted $4 \mathrm{~h}$. Femoral arteries were isolated 4 weeks after the intervention. Morphological analyses were performed as described in Methods. Values are expressed as the mean \pm SD ( $n=$ 10 arteries/group). ${ }^{\mathrm{a}} \mathrm{p}<0.05$, versus saline controls; ${ }^{\mathrm{b}} \mathrm{p}<0.01$, versus saline controls.
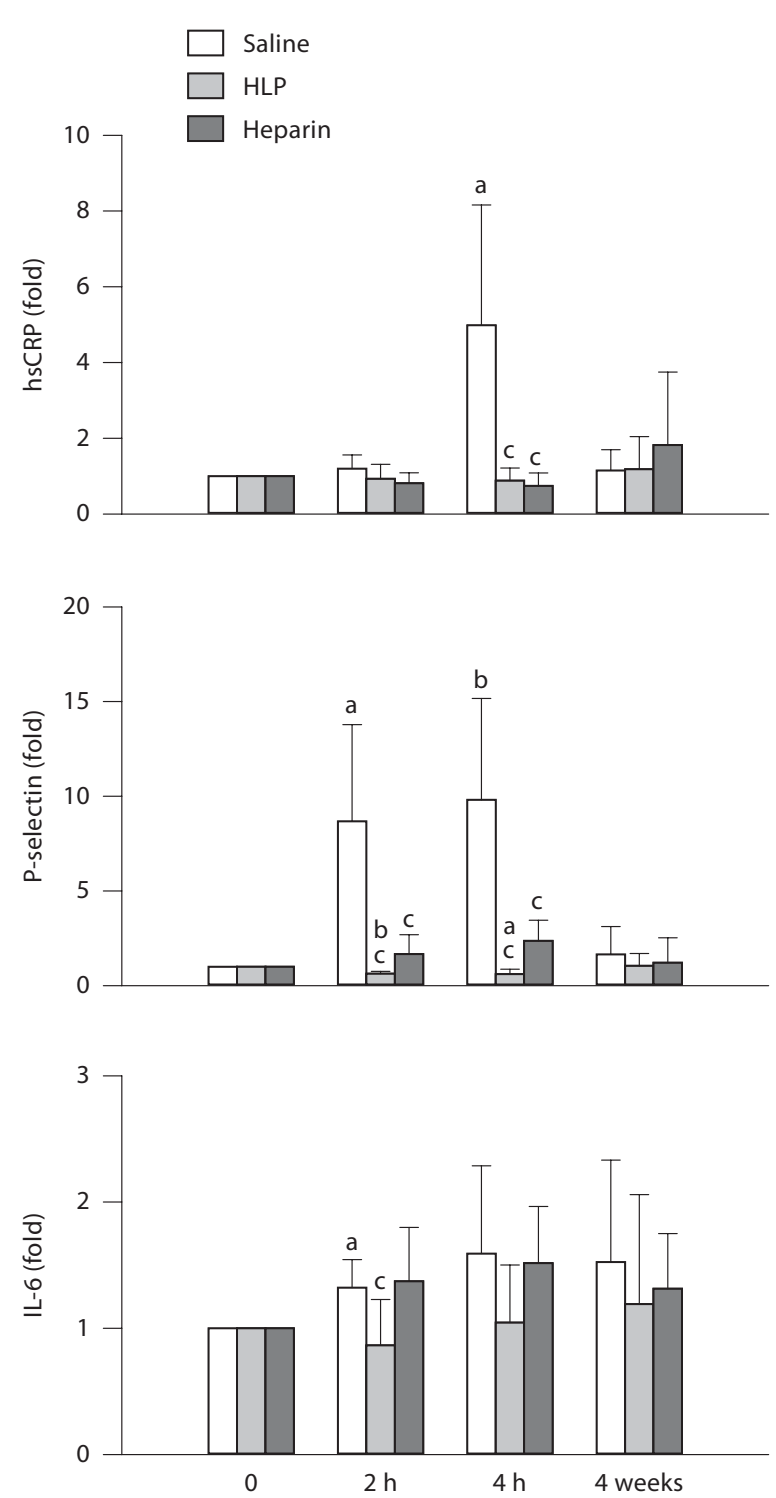

Fig. 3. Effects of HLP and heparin on serum hsCRP, P-selectin and IL- 6 in minipigs. Femoral arteries of minipigs were injured by balloon catheter. Animals received HLP $(1.6 \mathrm{mg} / \mathrm{kg} / \mathrm{h})$, heparin $(50 \mathrm{U} / \mathrm{kg} / \mathrm{h})$ or saline via the ear vein starting $0.5 \mathrm{~h}$ prior to the intervention and lasting for $4 \mathrm{~h}$. Blood samples were drawn through the internal jugular cannula immediately before, $2 \mathrm{~h}, 4 \mathrm{~h}$ and 4 weeks after vascular intervention. Serum hsCRP, P-selectin and IL- 6 were analyzed using specific ELISA kits. Values are expressed as the mean \pm SD ( $n=5$ animals). ${ }^{a} \mathrm{p}<0.05$, versus baseline; ${ }^{b} \mathrm{p}<0.01$, versus baseline; ${ }^{\mathrm{c}} \mathrm{p}<0.05$ versus saline control at the same time point. 


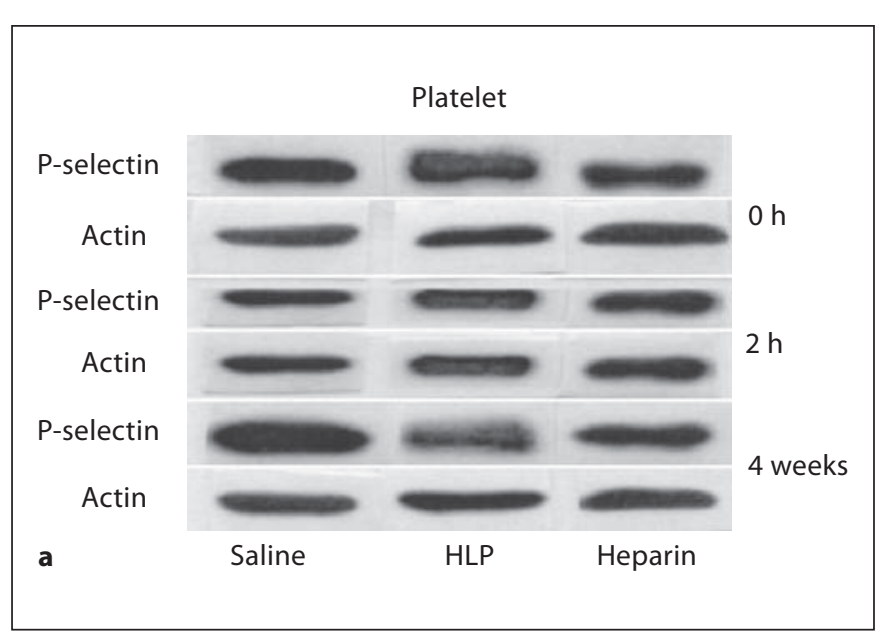

Fig. 4. Effect of HLP on the abundance of P-selectin in platelets of minipigs. Femoral arteries of minipigs were injured by balloon catheter dilation. Animals received HLP $(1.6 \mathrm{mg} / \mathrm{kg} / \mathrm{h})$, heparin $(50 \mathrm{U} / \mathrm{kg} / \mathrm{h})$ or saline via the ear vein for $4 \mathrm{~h}$ starting $0.5 \mathrm{~h}$ prior to the intervention. Blood samples were drawn through the internal jugular cannula immediately 4 weeks after the intervention.

lecular weight of P-selectin in cell lysates of platelets of minipigs was approximately $140 \mathrm{kDa}$ in Western blotting, which is similar to the dimer of human P-selectin as previously described [16]. The abundance of P-selectin was significantly increased in platelets 4 weeks, but not $2 \mathrm{~h}$, after vascular injury $(\mathrm{p}<0.05)$. HLP, but not heparin, normalized the injury-induced increase in platelet P-selectin in minipigs 4 weeks after vascular injury $(\mathrm{p}<$ $0.05)$. Heparin treatment did not significantly reduce platelet P-selectin (fig. 4).

\section{Discussion}

For the first time, the present study demonstrated the inhibitory effect of HLP on balloon catheter-induced neointimal formation in a large animal model. The cardiovascular system of swine is close to the human system compared with rodents or rabbits [17]. The swine model, especially minipigs, has been extensively used to assess the efficacy and safety of medications or the device for preventing vascular intervention-induced neointimal formation in preclinical studies [18]. HLP reduced vascular injury-induced neointimal formation and stenosis in minipigs in an extent similar to unfractured heparin, but caused evidently less change in coagulation activity compared with heparin. Our previous studies demonstrated

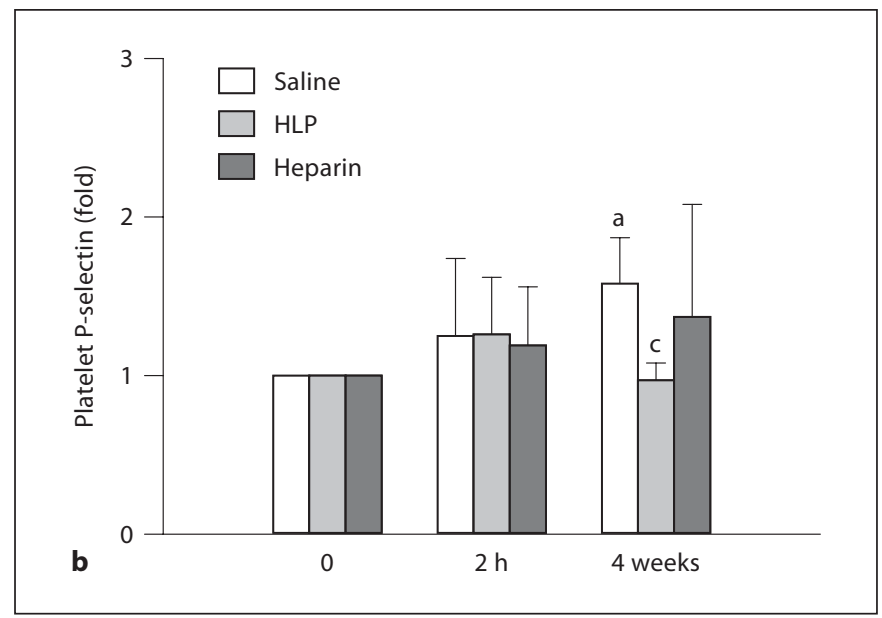

Platelets were freshly isolated and lysed. P-selectin in the platelet lysate was assessed using Western blotting. a Typical blots. b Integrative data. Values are expressed as the mean \pm SD $(n=5$ animals) after normalization with $\beta$-actin in the same samples. ${ }^{\mathrm{a}} \mathrm{p}<0.05$, versus baseline; ${ }^{\mathrm{c}} \mathrm{p}<0.05$, versus saline controls.

that hirulog-1, but not the equal molar concentration of HLP, significantly prolonged aPTT in rats [11]. Findings generated from the present study provide additional rationale for further examining the potential application of HLP in the prevention of vascular procedure-induced neointimal formation in humans.

The present study in minipigs supports our previous observations in rats and rabbits that a single perfusion of HLP started prior to vascular intervention may effectively prevent balloon catheter dilation-induced neointimal formation in large arteries. The findings support the hypothesis that thrombin plays a critical role in neointimal formation during the early stage of vascular injury. A single prolonged infusion of HLP started before vascular intervention may reduce thrombin formation at the site of vascular injury and prevent subsequent neointimal formation. The results of the present study on HLP are consistent with previous observations using other thrombinspecific inhibition peptides in a similar regimen [19]. A single intravenous infusion of HLP started before vascular intervention is feasible for elective vascular procedures.

The mechanism for the pathogenesis of vascular intervention-induced neointimal formation has not been completely understood. Inflammation has been considered as a cornerstone of vascular intervention-induced neointimal formation [20]. Mechanical stress during angioplasty 
or stenting may stimulate the production of inflammatory mediators in the vasculature. One of the initial steps of vascular inflammation is the binding of monocytes from blood circulation to the vascular wall mediated by cell adhesion molecules. Elevated levels of cell adhesion molecules (E-selectin, P-selectin) and inflammatory regulators (monocyte chemotactic protein 1, IL-6, IL-8) have been detected in the blood of humans or animals following invasive vascular procedures $[14,21,22]$. Thrombin is a potent activator for platelets and inflammation. Antithrombin III supplementation downregulated the elevated levels of inflammatory mediators, including CRP, cell adhesion molecules and proinflammation cytokines, in patients with severe sepsis [22]. The results of the present study demonstrated that the circulatory level of P-selectin was increased in control minipigs $2-4 \mathrm{~h}$ after balloon catheter injury. HLP, but not heparin, reduced platelet P-selectin 4 weeks, but not $2 \mathrm{~h}$, after vascular injury. The results suggest that HLP may inhibit both the release and production of P-selectin in platelets. The mechanism for HLP-induced reduction in P-selectin in platelets remains unclear, which may be investigated in subsequent studies.

The increase in circulatory IL- 6 in serum of minipigs was relatively moderate, which was detected only $2 \mathrm{~h}$ after vascular injury. HLP significantly reduced the levels of IL- 6 in minipigs $2 \mathrm{~h}$ after injury. The effect of HLP on IL6 is possibly related to its thrombin-specific inhibition, since heparin, a nonspecific thrombin inhibitor, did not significantly change the level of IL- 6 .

$\mathrm{CRP}$ is a nonspecific marker of inflammation. Elevated levels of hsCRP were associated with acute ischemic events and correlated with the extent of atherosclerosis and diabetic vascular complications [24, 25]. Increased hsCRP was detected in patients after angioplasty [26]. The role of CRP in the pathogenesis of ischemic events or restenosis remains unclear. The present study demonstrated that serum hsCRP in minipigs was increased after
$4 \mathrm{~h}$ of vascular injury, which returned to the basal level 4 weeks after vascular injury. HLP as well as heparin infusion prevented the increase in CRP in minipigs. The results of the present study suggest that the increased formation of CRP in blood circulation following balloon catheter injury may partially result from the increase in thrombin formation following vascular intervention.

Our previous studies demonstrated that HLP did not significantly or mildly elongate bleeding time or aPTT in rats or rabbits $[11,12,27]$. The results of the present study indicated that HLP did not significantly prolong aPTT in minipigs as well as in small animals $[11,12]$. The length of aPTT in HLP-treated minipigs was significantly shorter than those receiving heparin. The findings suggest that HLP may cause a relatively lower risk of interfering coagulation than unfractured heparin.

In conclusion, HLP effectively reduced balloon catheter-induced neointimal formation in minipigs without a significant alteration in coagulation activity. HLP treatment normalized vascular injury-induced increases in the circulatory levels of CRP, P-selectin and IL- 6 and reduced the content of P-selectin in platelets of minipigs. The anti-neointimal formation activity of HLP may partially result from its inhibitory effect on multiple inflammation mediators in minipigs.

\section{Acknowledgments}

The authors are grateful for the help from Dr. Wei-Feng Shen (Ruijing Hospital, Shanghai) and Dr. John Ducas (University of Manitoba) in angioplasty for animals. This study was supported by grants from the Heart and Stroke Foundation of Canada, the Canadian Institute of Health Research (RO-15296), the National Nature and Sciences Fund of China (30270549), the Science Foundation of Shanghai Jiaotong University, School of Medicine (02XJ21007) and the Health Sciences Centre Foundation, and the National Key Project for Basic Research (2006CB503804).

\section{References}

1 Libby P, Schwartz D, Brogi E, Tanaka H, Clinton SK: A cascade model for restenosis: a special case of atherosclerosis progression. Circulation 1992;86(suppl 6):III47-III52.

2 Clowes AW, Reidy MA: Prevention of stenosis after vascular reconstruction: pharmacologic control of intimal hyperplasia - a review. J Vasc Surg 1991;13:885-891.
-3 Mack MJ, Prince SL, Herbert M, Brown PP, Katz M, Palmer G, Edgerton JR, Eichhorn E, Magee MJ, Dewey TM: Current clinical outcomes of percutaneous coronary intervention and coronary artery bypass grafting. Ann Thorac Surg 2008;86:496-503.

4 Landzberg BR, Frishman WH, Lerrick K: Pathophysiology and pharmacological approaches for prevention of coronary artery restenosis following coronary artery balloon angioplasty and related procedures. Prog Cardiovasc Dis 1997;39:361-398.
5 Fenton JW II: Thrombin functions and antithrombotic intervention. Thromb Haemost 1995;74:493-498.

6 Rade JJ, Schulick AH, Virmani R, Dichek DA: Local adenoviral-mediated expression of recombinant hirudin reduces neointima formation after arterial injury. Nat Med 1996;2:293-298. 
7 Xue M, Fenton JW 2nd, Shen GX: Hirulog-1 reduces expression of platelet-derived growth factor in neointima of rat carotid artery induced by balloon catheter injury. J Vasc Res 2000;37:82-92.

$>8$ Shen GX: Development and current application of thrombin-specific inhibitors. Curr Drug Targets Cardiovasc Haemost Dis 2001; 1:41-49.

-9 A comparison of recombinant hirudin with heparin for the treatment of acute coronary syndrome: the Global Use of Strategies to Open Occluded Coronary Arteries (GUSTO) IIb Investigators. N Engl J Med 1996; 335:775-782.

10 Bittl JA, Feit F: A randomized comparison of bivalirudin and heparin in patients undergoing coronary angioplasty for post-infarction angina. Hirulog Angioplasty Study Investigator. Am J Cardiol 1998;82:43P-49P.

-11 Xue M, Ren S, Welch S, Shen GX: Hiruloglike peptide reduces balloon catheter-induced neointima formation in rat carotid artery without increase in bleeding tendency. J Vasc Res 2001;38:144-152.

>12 Chen X, Ren S, Ma MG, Dharmalingam S, Lu L, Xue M, Ducas J, Shen GX: Hirulog-like peptide reduces restenosis and expression of tissue factor and transforming growth factor-beta in carotid artery of atherosclerotic rabbits. Atherosclerosis 2003;169:31-40.

$\checkmark 13$ Ito T, Ikeda U: Inflammatory cytokines and cardiovascular disease. Cur Drug Targets Inflamm Allergy 2003;2:257-265.
14 Murasaki K, Kawana M, Murasaki S, Tsurumi Y, Tanoue K, Hagiwara N, Kasanuki H High P-selectin expression and low CD36 occupancy on circulating platelets are strong predictors of restenosis after coronary stenting in patients with coronary artery disease. Heart Vessels 2007;22:229-236.

15 Abendschein DR, Baum PK, Verhallen P, Eisenberg PR, Sullivan ME, Light DR: A novel synthetic inhibitor of factor Xa decreases early reocclusion and improves 24 -h patency after coronary fibrinolysis in dogs. J Pharmacol Exp Ther 2001;296:567-572.

16 Barkalow FJ, Barkalow KL, Mayadas TN: Dimerization of P-selectin in platelets and endothelial cells. Blood 2000;96:3070-3077.

17 Appel JZ 3rd, Buhler L, Cooper DK: The pig as a source of cardiac xenografts. J Card Surg 2001;16:345-356.

18 Carter AJ, Wei W, Gibson L, Collingwood R, Tio F, Dooley J, Kopia GA: Segmental vessel wall shear stress and neointimal formation after sirolimus-eluting stent implantation: physiological insights in a porcine coronary model. Cardiovasc Revasc Med 2005;6:5864.

19 Gallo R, Padurean A, Toschi V, Bichler J, Fallon JT, Chesebro JH, Fuster V, Badimon JJ: Prolonged thrombin inhibition reduces restenosis after balloon angioplasty in porcine coronary arteries. Circulation 1998;97:581588.

20 Schillinger M, Minar E: Restenosis after percutaneous angioplasty: the role of vascular inflammation. Vasc Health Risk Manag 2005; 1:73-78.

-21 Serrano CV Jr, Ramires JA, Venturinelli M, Arie S, D’Amico E, Zweier JL, Pileggi F, da Luz PL: Coronary angioplasty results in leukocyte and platelet activation with adhesion molecule expression. Evidence of inflammatory responses in coronary angioplasty. J Am Coll Cardiol 1997;29:1276-1283.
22 Hognestad A, Endresen K, Wergeland R, Mellembakken JR, Mollnes TE, Omland T, Kjekshus JK, Aukrust P, Andreassen AK: Inflammatory response and re-stenosis after percutaneous coronary intervention in heart transplant recipients and patients with native atherosclerosis. J Heart Lung Transplant 2005;24:1026-1032.

23 Inthorn D, Hoffmann JN, Hartl WH, Mühlbayer D, Jochum M: Effect of antithrombin III supplementation on inflammatory response in patients with severe sepsis. Shock 1998;10:90-96.

24 Menown IB, Mathew TP, Gracey HM, Nesbitt GS, Murray P, Young IS, Adgey AA: Prediction of Recurrent Events by D-Dimer and Inflammatory Markers in Patients with Normal Cardiac Troponin I (PREDICT) Study. Am Heart J 2003;145:986-992.

25 Kang ES, Kim HJ, Ahn CW, Park CW, Cha BS, Lim SK, Kim KR, Lee HC: Relationship of serum high sensitivity C-reactive protein to metabolic syndrome and microvascular complications in type 2 diabetes. Diabetes Res Clin Pract 2005;69:151-159.

26 Saleh N, Tornvall P: Serum C-reactive protein response to percutaneous coronary intervention in patients with unstable or stable angina pectoris is associated with the risk of clinical restenosis. Atherosclerosis 2007;195: 374-378.

27 Tang XF, Qian J, Wan DJ, Zhu JH, Gao PJ, Zhu DL, Shen GX: Pharmacokinetics and pharmacology of hirulog-like peptide. J Cardiovasc Pharmacol 2007;50:406-410. 